\title{
Lateral Hypothalamic Serotonin Inhibits Nucleus Accumbens Dopamine: Implications for Sexual Satiety
}

\author{
Daniel S. Lorrain, Jon V. Riolo, Leslie Matuszewich, and Elaine M. Hull \\ Department of Psychology, State University of New York at Buffalo, Buffalo, New York 14260
}

\begin{abstract}
Dopamine (DA) is released in several brain areas, including the nucleus accumbens (NAcc), before and during copulation in male rats. DA agonists administered into this area facilitate, and DA antagonists inhibit, numerous motivated behaviors, including male sexual behavior. Serotonin $(5-\mathrm{HT})$ is generally inhibitory to male sexual behavior. We reported previously that $5-\mathrm{HT}$ is released in the anterior lateral hypothalamic area $\left(\mathrm{LHA}_{\mathrm{A}}\right)$ and that a selective serotonin reuptake inhibitor microinjected into that area delayed and slowed copulation. Our present results, using high temporal resolution microdialysis, (1) confirm previous electrochemical evidence that extracellular levels of DA increase in the NAcc during copulation and decrease during the
\end{abstract}

Male sexual behavior in humans, nonhuman primates, and rodents is influenced by dopamine (DA) and serotonin (5-HT) neurotransmission (Bitran and Hull, 1987; Gorzalka et al., 1990; Zajecka et al., 1991; Meston and Gorzalka, 1992; Wilson, 1994; Melis and Argiolas, 1995). In general, DA enhances, whereas 5-HT inhibits, sexual motivation and performance and thus may contribute to initiation and satiety, respectively.

In the presence of sexually relevant stimuli, extracellular DA increases in the nucleus accumbens (NAcc) (Mas et al., 1990; Pfaus et al., 1990; Damsma et al., 1992; Fiorino et al., 1997) and the medial preoptic area (MPOA) (Hull et al., 1995) of male rats; DA levels increase further during copulation. DA remains elevated until the male ejaculates, after which DA levels decrease (Blackburn et al., 1992). After a postejaculatory interval (PEI) of sexual refractoriness, copulation resumes and is paralleled by enhanced DA release. This pattern has helped define a role for DA in facilitating male sexual behaviors. However, factors that inhibit DA release after ejaculation (and thus may contribute to the PEI) have received little attention.

Serotonin generally inhibits copulation. Sexual behavior is impaired by many 5-HT agonists and agents that increase 5-HT availability and is facilitated by serotonergic lesions and many receptor antagonists (Bitran and Hull, 1987; Gorzalka et al., 1990; Wilson, 1994). These experiments foster the hypothesis that endogenous 5-HT may be released at ejaculation and may regulate the PEI. Ex vivo preoptic tissue levels of 5-HT (Mas et al.,

\footnotetext{
Received April 9, 1999; accepted June 11, 1999.

This research was supported by National Institute of Mental Health Grant MH40826 to E.M.H.

Correspondence should be addressed to Dr. Elaine M. Hull, Department of Psychology, State University of New York at Buffalo, Buffalo, NY 14260.

Dr. Lorrain's present address: Department of Psychiatry, University of Chicago, MC 3077, 5841 South Maryland Avenue, Chicago, IL 60637.

Dr. Matuszewich's present address: Department of Psychiatry, Case Western Reserve University, 11100 Euclid Avenue, Cleveland, OH 44106-5000.

Copyright (C) 1999 Society for Neuroscience $0270-6474 / 99 / 197648-05 \$ 05.00 / 0$
}

postejaculatory interval (PEI) and (2) reveal that $\mathrm{LHA}_{\mathrm{A}} 5-\mathrm{HT}$ can inhibit both basal and female-elicited DA release in the NAcc. These findings suggest that the neural circuit promoting sexual quiescence during the PEI includes serotonergic input to the $\mathrm{LHA}_{\mathrm{A}}$, which in turn inhibits DA release in the NAcc. These findings may also provide insights concerning the inhibitory control of other motivated behaviors activated by the NAcc and may have relevance for understanding the sexual side effects common to antidepressant medications.

Key words: serotonin; lateral hypothalamic area; dopamine; nucleus accumbens; copulation; postejaculatory interval; microdialysis; male rats
1987) and in vivo preoptic microdialysate measures of 5-hydroxyindoleacetic acid [the main metabolite of 5-HT (Fumero et al., 1994)] increased significantly only after ejaculation. Thus, 5-HT may be released in serotonergic terminal fields, including the preoptic area, and promote sexual refractoriness during the PEI. We recently measured extracellular 5-HT in the MPOA but found no changes during copulation or after ejaculation (Lorrain et al., 1997). Extracellular 5-HT did, however, increase in the nearby anterior lateral hypothalamic area $\left(\mathrm{LHA}_{\mathrm{A}}\right)$ immediately after ejaculation. 5-HT in the $\mathrm{LHA}_{\mathrm{A}}$ subsequently decreased to near baseline levels before copulation resumed. Furthermore, microinjection of a selective serotonin reuptake inhibitor (SSRI) into the $\mathrm{LHA}_{\mathrm{A}}$ delayed the onset of copulation (similarly to the PEI) and delayed ejaculation after the male resumed copulation (Lorrain et al., 1997). Clearly, 5-HT release in the $\mathrm{LHA}_{\mathrm{A}}$ is inhibitory to copulation and may contribute to the PEI.

5-HT projections originating in the raphe may suppress forebrain catecholaminergic systems (Yamamoto and Ueki, 1978). The $\mathrm{LHA}_{\mathrm{A}}$ receives 5-HT input from the raphe (Veening et al., 1982; Vertes, 1991) and contributes efferent fibers that ascend or descend through the medial forebrain bundle (Saper et al., 1979; Hakan et al., 1992). We tested whether 5-HT released in the $\mathrm{LHA}_{\mathrm{A}}$ may suppress sexual activity by inhibiting the mesoaccumbens DA system. In experiment 1 we used microdialysis to confirm previous electrochemical data showing increased NAcc DA release during copulation and decreased release after ejaculation. In experiment 2, we administered 5-HT to the $\mathrm{LHA}_{\mathrm{A}}$ via reverse dialysis and simultaneously measured its effect on basal and female-elicited NAcc DA release.

\section{MATERIALS AND METHODS}

Subjects. Nineteen sexually experienced male rats were housed individually in plastic cages and maintained on a reverse light/dark cycle with lights off at 11:00 A.M. and on at 10:00 P.M. Food and water were available ad libitum. For experiment 1, 7 subjects received a unilateral 
guide cannula aimed at the shell region of the NAcc [anteroposterior, +3.0; mediolateral, +1.0; and dorsoventral, -5.2 (Pellegrino et al., 1979)]; the remaining 12 subjects, used in experiment 2, additionally received an ipsilateral guide cannula aimed at the $\mathrm{LHA}_{\mathrm{A}}$ [anteroposterior, +1.3; mediolateral, +1.5; and dorsoventral, -7.2 (Pellegrino et al., 1979)]. After a 1 week period of recovery, microdialysis sessions began. All procedures followed the guidelines of and were approved by the local Institutional Animal Care and Use Committee.

Microdialysis. Concentric microdialysis probes were constructed in the lab. Briefly, a 27 ga thin-wall stainless steel tube was fitted with a dialysis membrane [12,000 kDa cutoff; $210 \mu \mathrm{m}$ outer diameter (o.d.); $1 \mathrm{~mm}$ active-dialyzing surface; Spectra Por, Houston, TX] at one end and a 3 $\mathrm{cm}$ piece of polyethylene 20 tubing at the other end to serve as the inlet for the perfusion medium. A $20 \mathrm{~cm}$ piece of silica capillary tubing [125 $\mu \mathrm{m}$ o.d.; $50 \mu \mathrm{m}$ inner diameter (i.d.); Polymicro Technologies, Phoenix, AZ], threaded down into the dialysis tube, served as the outlet. For experiment 1 , the dialysate flow rate was $1 \mu \mathrm{l} / \mathrm{min}$; samples were collected every $3 \mathrm{~min}$ into microcentrifuge tubes $(250 \mu \mathrm{l})$, placed on dry ice, and injected within $1 \mathrm{hr}$ onto a capillary column for analysis of DA concentration by HPLC with electrochemical detection (HPLC-EC). For experiment 2 , the dialysate flow rate was $0.5 \mu \mathrm{l} / \mathrm{min}$, and samples were collected every $10 \mathrm{~min}$. For both experiments, the dialysis perfusion medium was a modified Ringer's solution consisting of $138 \mathrm{~mm} \mathrm{NaCl}, 2.7$ $\mathrm{mm} \mathrm{KCl}$, and $1.2 \mathrm{~mm} \mathrm{CaCl}_{2}, \mathrm{pH}$ 7.0. Flow was controlled by a Harvard syringe infusion pump (model 22; Cambridge, MA). On the morning of each microdialysis session, subjects were briefly anesthetized with ether to allow for insertion of the microdialysis probe(s). Flow of dialysate began immediately, and a $5 \mathrm{hr}$ stabilization period was allowed before sample collection began. All microdialysis data are presented as percentage of baseline [which was established by taking the average of three consecutive prefemale (experiment 1) or predrug (experiment 2) samples].

HPLC. Detection of DA was accomplished using capillary HPLC-EC. Each sample was loaded manually into a VALCO self-actuating injector valve, delivering $500 \mathrm{nl}$ to a C18 reverse-phase capillary column $(0.3 \mathrm{~mm}$ i.d. $\times 5.0 \mathrm{~cm} ; 3 \mu \mathrm{m}$ spheres; LC Packings, San Francisco, CA). The mobile phase consisted of $30 \mathrm{~mm}$ citric acid, $50 \mathrm{~mm}$ sodium acetate, 0.027 mM Na${ }_{2}$ EDTA, and $0.25 \mathrm{~mm}$ octyl sodium sulfate, with $2.5 \%$ acetonitrile and $0.2 \%$ tetrahydrofuran $(\mathrm{v} / \mathrm{v}), \mathrm{pH} 3.6$, and was delivered using a Gilson, Inc. (Middleton, WI) model 307 pump operating at $0.5 \mathrm{ml} / \mathrm{min}$ and equipped with an Acurate flow splitter (LC Packings). The flow splitter provided $6 \mu \mathrm{l} / \mathrm{min}$ of pulsation-free mobile phase to the analytical column. Dopamine oxidation was detected via an Antec DECADE controller (Leiden, The Netherlands) using a micro flow cell (11 nl volume) with a glassy carbon working electrode maintained at a potential of $+0.7 \mathrm{~V}$ relative to a $\mathrm{Ag} / \mathrm{AgCl}$ reference electrode. The system was calibrated daily with a freshly prepared DA standard at a concentration of $1 \mathrm{pg} / \mu \mathrm{l}(0.5 \mathrm{pg}$ on the column).

Procedures. In experiment 1 , after the $5 \mathrm{hr}$ stabilization period and after collection of baseline dialysate samples, an estrous female was introduced into the male's testing arena, and copulation began. The male was allowed to copulate for up to three ejaculations. During this time, samples were collected in $3 \mathrm{~min}$ bins and labeled as those collected during copulation (COP) and those collected during sexual quiescence after an ejaculation (PEI). Three groups of samples (based on the male's behavior during collection) were thus established for subsequent HPLC analysis of DA content: baseline (BL), COP, and PEI.

In experiment 2, after the $5 \mathrm{hr}$ stabilization period and after collection of baseline samples via the microdialysis probe located in the NAcc, flow was initiated in the probe located in the ipsilateral $\mathrm{LHA}_{\mathrm{A}}$, which delivered either 5-HT [1 mg/ml (5.6 mM); Sigma, St. Louis, MO] or vehicle (Ringer's solution). Dialysate samples continued to be collected from the NAcc in 10 min bins during 40 min of LHA perfusion. To test for 5-HT suppression of copulation-elicited NAcc DA release, we placed an estrous female into the male's testing arena during collection of the final sample, concurrent with $\mathrm{LHA}_{\mathrm{A}}$ 5-HT perfusion (i.e., time, 30-40 min after baseline). All males displayed some sexual behaviors; however, their performance was not scored.

Histology. After the microdialysis session, animals were deeply anesthetized with sodium pentobarbital, and cresyl violet dye was perfused through their microdialysis probe(s). Subjects were then decapitated, and their brains were removed for histological verification of probe placement. Only those animals with blue dye in the region of the NAcc (experiment 1) and $\mathrm{LHA}_{\mathrm{A}}$ (experiment 2) were used for statistical analysis.
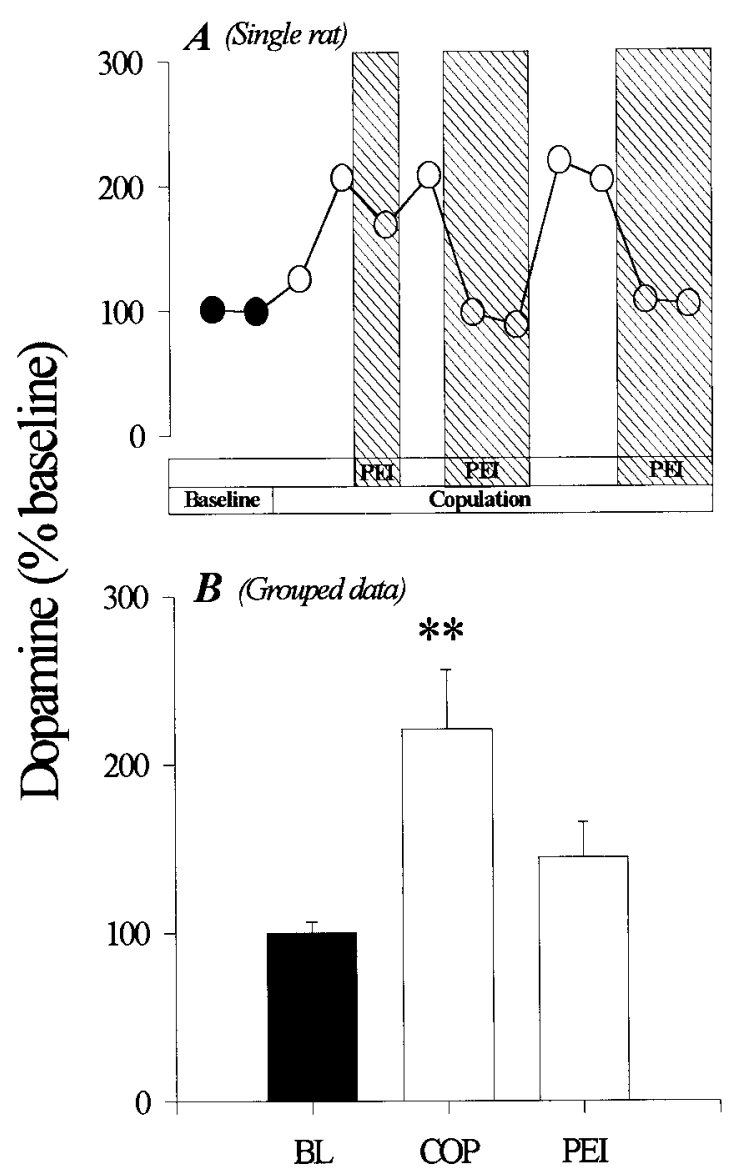

Figure 1. In vivo microdialysis of DA release from the NAcc of male rats during sexual behavior sessions. $A$, Representative example of temporal changes in a single rat. $B$, Mean change in DA release $( \pm$ SEM) for a group of six rats. Samples were collected at 3 min intervals during three ejaculatory series and are designated precopulatory BL (filled circles), COP (open circles), or PEI (hatched circles). Dopamine content was significantly greater in samples collected during copulation, compared with samples collected under BL and PEI conditions $\left({ }^{* *} p<0.05\right)$.

Data analysis. For experiment 1 , as noted above, dialysate collected from the NAcc was grouped into three behavioral categories: BL, COP, and PEI (expressed as percentages). A one-way ANOVA was conducted on the mean DA percentages for these three groups. Because the test for normality failed $(p<0.001)$, a Kruskal-Wallis one-way ANOVA on ranks was performed, followed by post hoc comparisons using the Dunn's method. For experiment 2, a two-way repeated measures ANOVA was used, with perfusate (5-HT vs vehicle) as the between factor and time (6 or 10 min dialysis bins) as the within factor, to test the effects of 5-HT perfusion into the $\mathrm{LHA}_{\mathrm{A}}$ on NAcc DA levels. Post hoc Scheffé comparisons were made according to Kirk (1968).

\section{RESULTS}

\section{Experiment 1: DA release in the NAcc during copulation and after ejaculation}

DA release in the NAcc followed a predictable pattern reflective of an activational role for this neurotransmitter in copulation. A typical pattern for an individual animal can be seen in Figure $1 A$; DA release was high during copulation but decreased after each ejaculation (i.e., during the PEI). The ANOVA on ranks for the grouped data revealed a significant difference in mean dialysate DA levels across behavioral categories $[H(2)=14.794 ; p<0.001$; Figure $1 B]$. Post hoc comparisons showed that DA was significantly higher in samples collected during copulation, compared with those collected during either BL or the PEI $(p<0.05)$. 


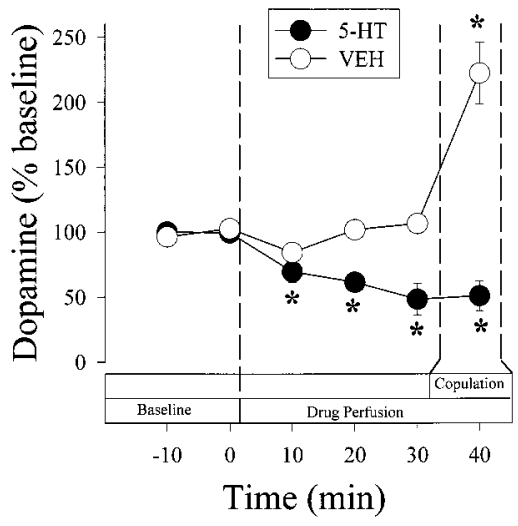

Figure 2. Temporal change in DA concentration of the dialysate collected from the NAcc before and during $40 \mathrm{~min}$ of 5 -HT perfusion into the $\mathrm{LHA}_{\mathrm{A}}$ of six male rats. Samples were collected at 10 min intervals. An estrous female was introduced to the male, and copulation was allowed during collection of the final sample during 5-HT perfusion. A significant decrease in DA occurred throughout the entire 5-HT perfusion period. This treatment blocked the increase in NAcc DA release seen in control animals $\left[{ }^{*} p<0.05\right.$, perfusion times vs time 0 (baseline)]. VEH, Vehicle.

\section{Experiment 2: effects of 5-HT in the LHA $A_{A}$ on DA in the NAcc}

Reverse dialysis of 5-HT into the $\mathrm{LHA}_{\mathrm{A}}$ decreased the basal release of NAcc DA and also prevented the enhanced release normally seen during copulation (Fig. 2). The ANOVA conducted on these data detected a significant effect of groups $\left[F_{(1,10)}\right.$ $=46.324 ; p<0.001]$ and time $\left[F_{(5,50)}=11.232 ; p<0.001\right]$ and a group $\times$ time interaction $\left[F_{(5,50)}=22.876 ; p<0.001\right]$. Post hoc comparisons revealed that DA was significantly lower in each of the four dialysate samples collected during 5-HT perfusion, compared with baseline values $(p<0.05)$. Animals receiving vehicle into the $\mathrm{LHA}_{\mathrm{A}}$ showed a significant increase in NAcc DA relative to baseline $(p<0.05)$ during copulation; however, no such increase was observed in the animals receiving 5-HT into the LHA $_{\mathrm{A}}$.

\section{DISCUSSION}

These findings demonstrate a neurochemical link between the hypothalamic and mesolimbic systems of the brain that may promote sexual quiescence during the PEI. In experiment 1 we established that extracellular DA levels increase in the NAcc of male rats during copulation but then decrease after ejaculation, during the PEI. Similar results have been reported, based on in vivo chronoamperometric techniques (Phillips et al., 1991). Although such techniques have high temporal resolution, they cannot completely dissociate the contributions of DOPAC and ascorbic acid from that of DA to the signal (Dayton et al., 1981; Gonon et al., 1984). Recently, using in vivo microdialysis, which has excellent neurochemical resolution, Fiorino et al. (1997) concluded that sexual satiation may be related to an inability of an estrous female to elicit an increase in NAcc DA levels. In that experiment a 15 min sampling period was used, preventing a description of individual ejaculatory sequences. The present experiment used a 3 min sampling interval, providing for the first time both high temporal resolution and neurochemical resolution in a fine-grained analysis of DA release during specific behavioral episodes. The enhancement of NAcc DA release during copulation was not maintained throughout the PEI. This suggests that the DA-enhancing properties of the estrous female are somehow filtered or inhibited immediately after an ejaculation.

Lateral hypothalamic 5-HT levels, which increase after ejaculation, may contribute to the sexual quiescence of the PEI. Administering 5-HT into the $\mathrm{LHA}_{\mathrm{A}}$ via reverse dialysis in experiment 2, like ejaculation, produced an immediate decrease in the extracellular levels of DA in the NAcc. Dopamine continued to decline steadily throughout 5-HT administration. This treatment also prevented the female-elicited DA increase that is normally associated with copulation.

We reported recently that extracellular 5-HT increased in the $\mathrm{LHA}_{\mathrm{A}}$ after ejaculation; microinjection of an SSRI into this region delayed the onset of sexual activity (similarly to the PEI) and also delayed ejaculation after copulation began but did not interfere with general locomotion (Lorrain et al., 1997). These data, together with the current findings, suggest that the abrupt halt in copulation after an ejaculation may be, in part, regulated by the release of 5-HT in the $\mathrm{LHA}_{\mathrm{A}}$ and the consequent inhibition of mesoaccumbens DA. Under normal conditions, DA is released within the NAcc of male rats when estrous cues are present (Louilot et al., 1991; Damsma et al., 1992). This DA may activate the male to copulate with the female. DA-depleting lesions of the NAcc decreased the number of penile erections in response to remote stimuli from an estrous female and delayed the onset of copulation (Liu et al., 1998). During the PEI, NAcc DA levels decrease (experiment 1 ), as does the display of sexual advances toward a female. The rise of 5-HT in the LHA $\mathrm{A}_{\mathrm{A}}$ may be an important factor inhibiting neuronal processes that normally activate mesoaccumbens DA and appetitive behaviors.

Inhibitory control over copulation during the PEI is an important factor in reproductive success. Too early resumption of copulation would dislodge the sperm plug that promotes sperm transport to the female's uterus (Adler and Zoloth, 1970; Sachs, 1982); furthermore, a second ejaculate occurring soon after the first would have fewer sperm than the preceding one. The sexual quiescence of the PEI is not a result of erectile failure; reflexive erections are maintained, or actually enhanced, by a preceding ejaculation (O'Hanlon and Sachs, 1980). Therefore, it is important for the male (and female) to be motivationally inhibited during the PEI to promote a successful pregnancy. The concurrent decrease in $\mathrm{LHA}_{\mathrm{A}}$ 5-HT (Lorrain et al., 1997) and increase in NAcc DA at the end of the PEI suggest a means for timing this period of sexual quiescence. The observation of two concurrent processes does not establish the direction of causation. However, the finding that reverse dialysis of 5-HT into the $\mathrm{LHA}_{\mathrm{A}}$ decreases extracellular levels of DA in the NAcc suggests that the postejaculatory rise in 5-HT in the $\mathrm{LHA}_{\mathrm{A}}$ normally causes the decrease in NAcc DA.

The $\mathrm{LHA}_{\mathrm{A}}$ may be well suited for modulating sexually relevant information from the hypothalamus to the rest of the brain. The lateral zone of the hypothalamus has been described as controlling arousal and motivated behavior (Benarroch, 1993). Numerous neurons in the lateral hypothalamus $(\mathrm{LH})$ rapidly changed their firing rates in response to jugular injections of either testosterone or estrogen (Orsini, 1982) and also to direct application of these hormones (Orsini, 1985). Furthermore, semiquantitative 2-deoxyglucose analysis of neural activation revealed an increase of neural activity in the LH in response to female odors (Orsini et al., 1985). Therefore, LH neurons may promote male sexual interest and/or activity. In addition, parasagittal cuts separating the MPOA from the $\mathrm{LHA}_{\mathrm{A}} /$ medial forebrain bundle impaired 


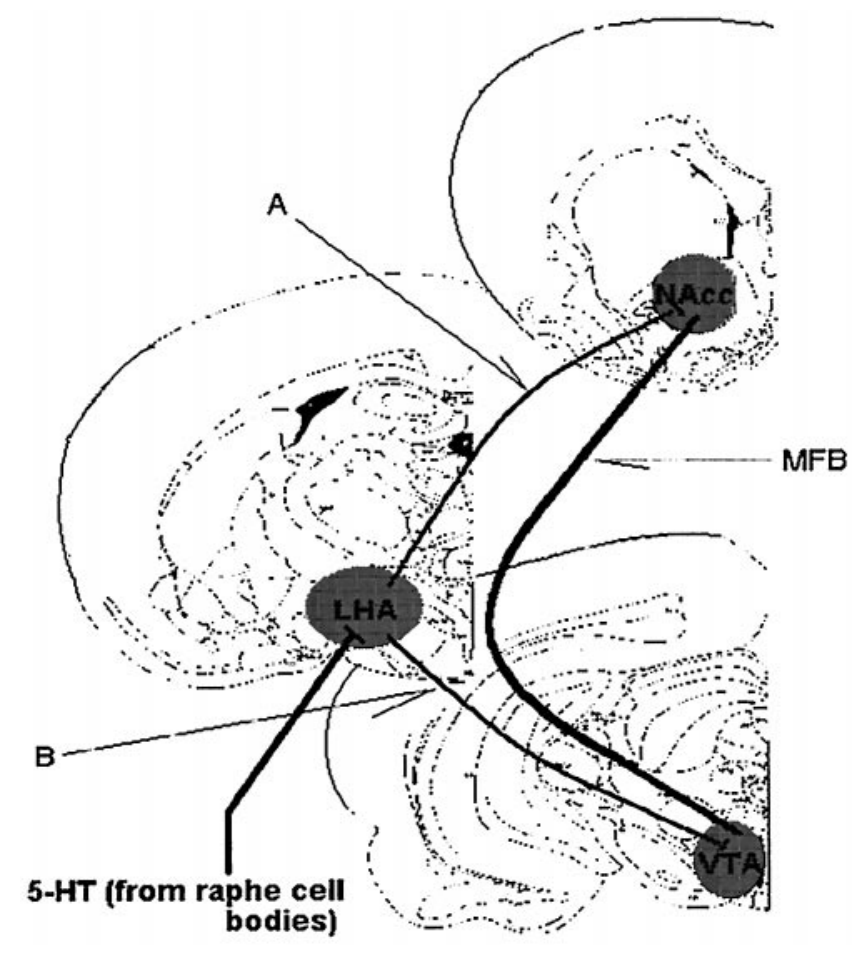

Figure 3. Schematic representation of possible neural circuits involved in $\mathrm{LHA}_{\mathrm{A}}$ 5-HT inhibition of NAcc DA release. DA release may be influenced from 5-HT acting on direct projections from the $\mathrm{LHA}_{\mathrm{A}}$ to the NAcc $(A)$ or indirect projection neurons reaching the VTA $(B)$. Adapted from Paxinos and Watson (1982). MFB, Medial forebrain bundle.

copulation in male rats (Szechtman et al., 1978; Brackett and Edwards, 1984).

There are at least two potential pathways that may mediate $\mathrm{LHA}_{\mathrm{A}}$ 5-HT influences on NAcc DA release (Fig. 3). The LHA is included in a group of structures that comprise the subpallidal area, which has been shown to have reciprocal connections with the NAcc (Hakan et al., 1992; Wu et al., 1996). There is also anatomical evidence of a descending pathway from the LH to the ventral tegmental area (VTA) (Wolf and Sutin, 1966; Saper et al., 1979). Thus, DA release in the NAcc could be directly influenced via the ascending pathway from the LHA to the NAcc or indirectly modulated via the descending pathway from the LHA to the VTA.

The NAcc terminal field is comprised of two main subregions, the shell and the core (for review, see Deutch et al., 1993). In the present study, microdialysis probe placements were restricted to the shell and therefore reflect $\mathrm{LHA}_{\mathrm{A}}$ 5-HT control over this subregion. It is unclear whether the core is similarly influenced. Such information may provide insight into differences between these two subregions in the control of motivated behaviors.

Although copulation did not elicit a DA response in the NAcc ipsilateral to the 5-HT reverse dialysis (experiment 2), all males were able to copulate, possibly because of normal DA activity in the unaffected contralateral hemisphere. Behavioral parameters were not recorded, so it is impossible to know whether 5-HT animals were different from controls. However, bilateral microinjections of an SSRI into the $\mathrm{LHA}_{\mathrm{A}}$ did delay and slow copulation in a previous experiment (Lorrain et al., 1997). DA-depleting lesions of the NAcc also delayed copulation onset (Liu et al., 1998), and decreasing NAcc DA release delayed and slowed copulation (Hull et al., 1991), suggesting that the NAcc DA is not necessary for copulation but does promote its onset.

These findings may have relevance for serotonergic control over other behaviors. Mesoaccumbens DA activity contributes to the activational impetus for many forms of motivated behavior (Koob, 1996; Salamone et al., 1997). The fact that increased extracellular 5-HT in the $\mathrm{LHA}_{\mathrm{A}}$ can inhibit NAcc DA release suggests that increased $\mathrm{LHA}_{\mathrm{A}}$ 5-HT may affect many behaviors. For example, extracellular DA in the NAcc is elevated before and during consumption of a meal and falls sometime afterward (Wilson et al., 1995). Furthermore, LHA 5-HT release increases during meal consumption and has been suggested as one factor promoting satiety (Schwartz et al., 1989; Aoyagi et al., 1992). DA, as well as 5-HT, in the LHA may inhibit NAcc DA release and behavioral reinforcement (Parada et al., 1995). Therefore, both 5-HT and DA release in the $\mathrm{LHA}_{\mathrm{A}}$ may form part of the neural circuitry responsible for terminating appetitive behaviors, perhaps by inhibiting stimulus-bound NAcc DA activation.

The present data may also provide insight into the effects of altered 5-HT activity on electrical self-stimulation of the brain and intravenous drug self-administration. These behaviors are under the control of mesoaccumbens DA activity (for review, see Di Chiara, 1995) and can be enhanced or inhibited by decreasing or increasing, respectively, 5-HT neurotransmission [electrical brain stimulation (Poschel and Ninteman, 1971; Katz and Carroll, 1977; Montgomery et al., 1991; Olds and Yuwiler, 1992; Fletcher et al., 1995) and intravenous drug self-administration (Carroll et al., 1990a,b; Loh and Roberts, 1990; Richardson and Roberts, 1991)]. There is, however, a recent report showing that stimulation of the $5-\mathrm{HT}_{1 \mathrm{~B}}$ receptor subtype may actually enhance cocaine reinforcement and thus cocaine self-administration behavior (Parsons et al., 1998). Nonetheless, the present findings suggest a central site that may mediate the suppressive effects of 5-HT on self-stimulation and -administration behaviors. Thus, $\mathrm{LHA}_{\mathrm{A}}$ 5-HT may be an important factor to consider when developing strategies for the treatment of drug abuse.

In conclusion, extracellular DA in the NAcc increased during copulation but then decreased after ejaculation. Elevating $\mathrm{LHA}_{\mathrm{A}}$ 5-HT via reverse dialysis decreased extracellular DA during both basal conditions and copulation. These data, together with previous findings (Lorrain et al., 1997), suggest that LHA $_{\mathrm{A}}$ 5-HT exerts inhibitory control over copulation, in part, by inhibiting NAcc DA release after an ejaculation. This research has important clinical implications for those taking SSRI antidepressants, major side effects of which are impairment of ejaculatory and orgasmic ability and decreased libido. It also suggests a central site in which 5-HT may exert inhibitory control over other motivated behaviors.

\section{REFERENCES}

Adler NT, Zoloth SR (1970) Copulatory behavior can inhibit pregnancy in female rats. Science 168:1480-1482.

Aoyagi K, Oomura Y, Shimizu N (1992) Concurrent measurement of serotonin metabolism and single neuron activity changes in the lateral hypothalamus of freely behaving rat. Behav Brain Res 49:205-212.

Benarroch EE (1993) The central autonomic network: functional, organizational, dysfunctional, and perspective. Mayo Clin Proc 68:988-1001.

Bitran D, Hull EM (1987) Pharmacological analysis of male rat sexual behavior. Neurosci Biobehav Rev 11:365-389.

Blackburn JR, Pfaus JG, Phillips AG (1992) Dopamine functions in appetitive and defensive behaviors. Prog Neurobiol 39:247-279.

Brackett NL, Edwards DA (1984) Medial preoptic connections with the midbrain tegmentum are essential for male sexual behavior. Physiol Behav 32:79-84.

Carroll ME, Lac ST, Asencio M, Kragh R (1990a) Fluoxetine reduces 
intravenous cocaine self-administration in rats. Pharmacol Biochem Behav 35:237-244.

Carroll ME, Lac ST, Asencio M, Kragh R (1990b) Intravenous cocaine self-administration is reduced by dietary L-tryptophan. Psychopharmacology (Berl) 100:293-300.

Damsma G, Pfaus JG, Wenkstern D, Phillips AG, Fibiger HC (1992) Sexual behavior increases dopamine transmission in the nucleus accumbens and striatum of male rats: comparison with novelty and locomotion. Behav Neurosci 106:181-191.

Dayton MA, Ewing AG, Wightman RM (1981) Evaluation of amphetamine-induced in vivo electrochemical response. Eur J Pharmacol 75:141-144.

Deutch AY, Bourdelais AJ, Zahm DS (1993) The nucleus accumbens core and shell: accumbal compartments and their functional attributes. In: Limbic motor circuits and neuropsychiatry (Kalivas PW, Barnes CD, eds), pp 45-88. Boca Raton, FL: CRC.

Di Chiara G (1995) The role of dopamine in drug abuse viewed from the perspective of its role in motivation. Drug Alcohol Depend 38:95-137.

Fiorino DF, Coury A, Phillips AG (1997) Dynamic changes in nucleus accumbens dopamine efflux during the Coolidge effect in male rats. J Neurosci 17:4849-4855.

Fletcher PJ, Tampakers M, Yeomans JS (1995) Median raphe injections of 8-OH-DPAT lower frequency thresholds of lateral hypothalamic self-stimulation. Pharmacol Biochem Behav 52:65-71.

Fumero B, Fernandez-Vera JR, Gonzalez-Mora JL, Mas M (1994) Changes in monoamine turnover in forebrain areas associated with masculine sexual behavior: a microdialysis study. Brain Res 662:233-239.

Gonon FG, Navarre F, Buda MJ (1984) In vivo monitoring of dopamine release in the rat brain with differential normal pulse voltammetry. Anal Chem 56:573-575.

Gorzalka BB, Mendelson SC, Watson NV (1990) Serotonin receptor subtypes and sexual behavior. Ann NY Acad Sci 600:435-446.

Hakan RL, Berg GI, Henriksen SJ (1992) Electrophysiological evidence for reciprocal connectivity between the nucleus accumbens septi and ventral pallidal regions. Brain Res 581:344-350.

Hull EM, Weber MS, Eaton RC, Dua R, Markowski VP, Lumley L, Moses J (1991) Dopamine receptors in the ventral tegmental area affect motor, but not motivational or reflexive, components of copulation in male rats. Brain Res 554:72-76.

Hull EM, Du J, Lorrain DS, Matuszewich L (1995) Extracellular dopamine in the medial preoptic area: implications for sexual motivation and hormonal control of copulation. J Neurosci 15:7465-7471.

Katz RJ, Carroll BJ (1977) Intracranial reward after Lilly 110140 (fluoxetine $\mathrm{HCl}$ ): evidence for an inhibitory role for serotonin. Psychopharmacology (Berl) 51:189-193.

Kirk RE (1968) Experimental design: procedures for the behavioral sciences. Pacific Grove, CA: Brooks/Cole.

Koob GF (1996) Hedonic valence, dopamine and motivation. Mol Psychiatry 1:186-189.

Liu YC, Sachs BD, Salamone JD (1998) Sexual behavior in male rats after radiofrequency or dopamine-depleting lesions in nucleus accumbens. Pharmacol Biochem Behav 60:585-592.

Loh EA, Roberts DC (1990) Break-points on progressive ratio schedule reinforced by intravenous cocaine increase following depletion of forebrain serotonin. Psychopharmacology (Berl) 101:262-266.

Lorrain DS, Matuszewich L, Friedman RD, Hull EM (1997) Extracellular serotonin in the lateral hypothalamic area is increased during the postejaculatory interval and impairs copulation in male rats. J Neurosci 17:9361-9366.

Louilot A, Gonzalez-Mora JL, Guadalupe T (1991) Sex-related olfactory stimuli induce a selective increase in dopamine release in the nucleus accumbens of male rats. A voltammetric study. Brain Res 553:313-317.

Mas M, Rodriguez del Castillo A, Guerra M, Davidson JM, Battaner E (1987) Neurochemical correlates of male sexual behavior. Physiol Behav 41:341-345.

Mas M, Gonzalez-Mora J, Louilot A, Sole C, Guadalupe T (1990) Increased dopamine release in the nucleus accumbens of copulating male rats as evidenced by in vivo voltammetry. Neurosci Lett 110:303-308.

Melis MR, Argiolas A (1995) Dopamine and sexual behavior. Neurosci Biobehav Rev 19:19-38.

Meston CM, Gorzalka BB (1992) Psychoactive drugs and human sexual behavior: the role of serotonergic activity. J Psychoactive Drugs 24:1-40.

Montgomery AM, Rose IC, Herberg LJ (1991) 5-HT $\mathrm{HA}_{1 \mathrm{~A}}$ agonists and dopamine: the effects of 8-OH-DPAT and buspirone on brainstimulation reward. J Neural Transm Gen Sect 83:139-148.

O'Hanlon JK, Sachs BD (1980) Penile reflexes in rats after different numbers of ejaculations. Behav Neural Biol 29:338-348.

Olds ME, Yuwiler A (1992) Effects of acute and chronic fenfluramine on self-stimulation and its facilitation by amphetamine. Eur J Pharmacol 216:363-272.

Orsini JC (1982) Androgen influence on lateral hypothalamus in the male rat: possible behavioral significance. Physiol Behav 29:979-987.

Orsini JC (1985) Direct effects of androgens on lateral hypothalamic neuronal activity in the male rat. II. A pressure ejection study. Brain Res Bull 15:547-552.

Orsini JC, Jourdan F, Cooper HM, Monmaur P (1985) Influence of female odors on lateral hypothalamus in the male rat. Semiquantitative deoxyglucose analysis. Physiol Behav 35:509-516.

Parada MA, Puig de Parada M, Hoebel BG (1995) Rats self-inject a dopamine antagonist in the lateral hypothalamus where it acts to increase extracellular dopamine in the nucleus accumbens. Pharmacol Biochem Behav 52:179-187.

Parsons LH, Friedbert W, Koob GF (1998) Serotonin SB $_{18}$ receptor stimulation enhances cocaine reinforcement. J Neurosci 18:10078-10089.

Paxinos G, Watson C (1982) The rat brain in stereotaxic coordinates. New York: Academic.

Pellegrino LJ, Pellegrino AS, Cushman AJ (1979) A stereotaxic atlas of the rat brain, Second edition. New York: Plenum.

Pfaus JG, Damsma G, Nomikos GG, Wenkstern D, Blaha CD, Phillips AG, Fibiger HC (1990) Sexual behavior enhances central dopamine transmission in the male rat. Brain Res 530:345-348.

Phillips AG, Pfaus JG, Blaha CD (1991) Dopamine and motivated behavior: insights provided by in vivo analyses. In: The mesolimbic dopamine system: from motivation to action (Willner P, Scheel-Kruger J, eds), pp 199-224. New York: Wiley.

Poschel BP, Ninteman FW (1971) Intracranial reward and the forebrain's serotonergic mechanism: studies employing para-chlorophenylalanine and para-chloroamphetamine. Physiol Behav 7:39-46.

Richardson NR, Roberts DC (1991) Fluoxetine pretreatment reduces breaking points on a progressive ratio schedule reinforced by intravenous cocaine self-administration. Life Sci 49:833-840.

Sachs BD (1982) Role of striated penile muscles in penile reflexes, copulation, and induction of pregnancy in the rat. J Reprod Fertil 66:433-443.

Salamone JD, Cousins MS, Snyder BJ (1997) Behavioral functions of nucleus accumbens dopamine: empirical and conceptual problems with the anhedonia hypothesis. Neurosci Biobehav Rev 21:341-359.

Saper CB, Swanson LW, Cowan WM (1979) An autoradiographic study of the efferent connections of the lateral hypothalamic area in the rat. J Comp Neurol 183:689-706.

Schwartz DH, McClane S, Hernandez L, Hoebel BG (1989) Feeding increases extracellular serotonin in the lateral hypothalamus of the rat as measured by microdialysis. Brain Res 479:349-354.

Szechtman H, Caggiula AR, Wulkan D (1978) Preoptic knife cuts and sexual behavior in male rats. Brain Res 150:569-595.

Veening JG, Swanson L, Maxwell W, Nieuwenhuys R, Geeraedts LM (1982) The medial forebrain bundles of the rat. II. An autoradiographic study of the major descending and ascending components. J Comp Neurol 52:82-108.

Vertes RP (1991) A PHA-L analysis of ascending projections of the dorsal raphe nucleus in the rat. J Comp Neurol 313:643-668.

Wilson C, Nomikos GG, Collu M, Fibiger HC (1995) Dopaminergic correlates of motivated behavior: importance of drive. J Neurosci 15:5169-5178.

Wilson CA (1994) Pharmacological targets for the control of male and female sexual behaviour. In: Sexual pharmacology (Riley AJ, Peet M, Wilson CA, eds), pp 1-58. Oxford: Oxford Medical Publications.

Wolf G, Sutin J (1966) Fiber degeneration after lateral hypothalamic lesions in the rat. J Comp Neurol 127:137-156.

Wu M, Hrycyshyn AW, Brudzynski SM (1996) Subpallidal outputs to the nucleus accumbens and the ventral tegmental area: anatomical and electrophysiological studies. Brain Res 740:151-161.

Yamamoto T, Ueki S (1978) Effects of drugs on hyperactivity and aggression induced by raphe lesions in rats. Pharmacol Biochem Behav 9:821-826.

Zajecka J, Fawcett J, Schaff M, Jeffriess H, Guy C (1991) The role of serotonin in sexual dysfunction: fluoxetine-associated orgasm dysfunction. J Clin Psychiatry 52:66-68. 